\title{
THE ROLE OF DIFFERENTIATION STRATEGY IN LOCAL TELECOMMUNICATION ENTRY AND MARKET EVOLUTION: 1999-2002*
}

\author{
Shane Greenstein $\dagger$ \\ Michael Mazzeo $\ddagger$
}

\begin{abstract}
We examine the role of differentiation among competitive local exchange carriers (CLECs) in nearly 1,200 U.S. cities in 1999 and 2002, before and after a valuation crash affecting communications firms. We test and reject the null hypothesis of homogeneous competitors. We also find strong evidence that differentiated CLECs account for both potential market demand and the business strategies of competitors when making their entry decisions. Finally, product heterogeneity in markets in 1999 helps predict how the structure of markets evolved through 2002 . We conclude that the policy debate for local telecommunications regulation should account for differentiated behavior.
\end{abstract}

\section{INTRODUCTION AND OVERVIEW}

By the end of the 1990's many cities in the United States had experience with competitive local telephony. In many locales competitive local exchange carriers (CLECs) entered into competition with each other and with the Incumbent Local Exchange Carrier (ILEC). In 1999, CLECs accounted for over \$20 billion in annual revenue (New Paradigm Resources Group [hereafter NPRG], 2000). The 1996 Telecommunications Act [also termed the Telecom Act] is partially responsible for this experience. Though it went through multiple court-tests and regulatory reviews in its first decade of existence, it provided a new national legal framework for interconnection and competition between ILECs and CLECs.

*We thank the Searle Foundation and Kellogg School of Management for funding.We thank Austan Goolsbee, Greg Rosston, Bill Rogerson, Glenn Woroch, Dennis Yao, the editor and two anonymous referees for many useful remarks, as well as seminar participants at Carnegie-Mellon, Cornell, Syracuse and Washington Universities, the NBER IO Winter 2003 meeting, the Transportation and Public Utilities Group session at the 2004 AEA meeting, and the Conference on Management Strategy and the Business Environment at the Harvard Business School. Avi Goldfarb provided excellent research assistance. We are grateful to Greg Rosston and Brad Wimmer for providing us data on ILECs. All errors are our responsibility.

$\dagger$ Authors’ affiliations: Kellogg School of Management, Northwestern University, 2001 Sheridan Road, Evanston, Illinois 60208, U.S.A.

e-mail: greenstein@kellogg.northwestern.edu

$\ddagger$ Kellogg School of Management, Northwestern University, 2001 Sheridan Road, Evanston, Illinois 60208, U.S.A.

e-mail:mazzeo@kellogg.northwestern.edu

(C) Blackwell Publishing Ltd. 2006, 9600 Garsington Road, Oxford OX4 2DQ, UK, and 350 Main Street, Malden, MA 02148, USA. 
Several studies have examined why some locales experienced more entry than others; in this paper we analyze whether differentiation among service offerings helps to explain CLEC entry behavior across markets after the Telecom Act. Although some research analyzes how CLECs compete with an ILEC after entry, we fill a gap in competitive analysis by highlighting how CLECs compete with each other. Focusing our study on differentiation addresses one motivation behind the Telecom Act, namely, to encourage variety in the services available in competitive local telecommunication markets.

Heterogeneity in CLEC offerings can take several forms. While telephone dial-tone and voice services are the core of an ILEC's business, these may be only a part of a larger portfolio of a CLECs offerings. CLECs may potentially offer a bundle including data services, networking services and other activities affiliated with operating communications at a customer's premises. Many CLECs claimed in their marketing literature that differences in quality, performance, and portfolio of services were important to potential customers. Many industry analysts have debated these claims. Our study provides important contributions to the literature by introducing statistical rigor into this debate, placing emphasis on measuring what firms do and making inferences from observed outcomes. Specifically, we inquire whether the entry behavior of local and national carriers indicates that they compete in different segments of the market for telephony.

Our empirical analysis employs the entry model in Mazzeo's [2002] study. The model statistically tests a null hypothesis of homogeneous competitors against an alternative that measures the differential impact of heterogeneous competitors. We develop a near census of entry across as many markets as possible, extending the census into many medium and small cities. We construct a data set derived from NPRG, which publishes a biannual census on CLEC activity. These reports track CLEC entry at the city level and describe the strategy of each CLEC in some detail.

The volatile financial performance of CLECs raises challenges for our research goals. We expect differentiating behavior to change over time in response to changes in economic determinants. Between 1999 and 2002 there were notable changes in (1) regulatory rules, (2) the opinions of investors about the presence of demand in particular locations and the viability of different modes of differentiation and (3) the stock market value of publicly traded firms in this market. While we cannot address all these changes, we can assess whether our conclusions about differentiation are sensitive to changes in regulatory decisions over interconnection prices, a costly-factor that changed in many locations during these three years. We also ask whether differentiation in 1999 appeared to shape entry in 2002, if at all, and whether that influence is consistent with the premises of our model.

Our results demonstrate a central role for differentiation strategies. First, we reject the null hypothesis of homogenous product competition in entry behavior. We find that otherwise equivalent markets support more CLECs of 
different types than CLECs of a similar type. Second, we find strong evidence that different types of firms react differently to similar economic determinants of entry, such as regulatory incentives and demographic composition of demanders. These findings are important and robust: heterogeneous services are as responsible for market entry as other demographic and regulatory factors. In addition, these quantitative results arise in 2002 as well as in 1999, despite the industry upheaval during the intervening years.

Our study is primarily statistical in focus, but it also does inform policy. The empirical findings confirm that regulatory rules and decisions are significant for entry decisions and can have the scope to encourage or discourage the entry of particular types of CLECs into medium-sized and smaller cities. Furthermore, we conclude that the FCC's practice of measuring competitiveness by merely counting the number of firms can be grossly misleading. Our results provide implications about how entrants can differ and how and where consumers would value variety. Thus, a more appropriate checklist for measuring local competition should incorporate the types of services offered by each of the CLECs.

\section{THE ECONOMICS OF CLEC MARKET ENTRY}

An empirical analysis of CLEC entry starts with three elements: the costs of entering and operating, the size of local market demand, and the regulatory setting. Based on these, inferences can be made about the relationship between market competition and the number of operating CLECs. A model of differentiated entry can provide insights on two additional dimensions. First, when differentiation is possible, firms may prefer to enter in markets where their competitors offer different types of services because the resulting competition is less tough. In addition, heterogeneous firms may respond asymmetrically to similar economic opportunities represented by cost, demand and regulation. ${ }^{1}$

Costs and Demand: As in prior work about entry (Bresnahan and Reiss [1991], Zolneirek, Eisner and Burton [2001]) we begin with the hypothesis that CLECs require that their fixed entry expenses be covered by a sufficient level of post-entry variable profits. Hence, CLEC entry behavior is influenced by the presence of fixed costs. Whether CLECs build their own facilities or lease part of their network from the ILEC, CLECs incur costs to set up and maintain the infrastructure needed to offer services. These fixed costs range from engineering costs to marketing expenses to costs associated with negotiating interconnection agreements.

There are differences across cities in the costs of providing CLEC services, including both fixed and operating costs. One source of such differences may

\footnotetext{
${ }^{1}$ Differentiation in offered services has not been addressed explicitly in prior empirical CLEC studies. Prior empirical work on CLEC entry includes Crandall's [2001], Crandall and Sidek's [2001] and Abel's [2002] studies, and several FCC reports described above that provide counts of operating firms.
} 
relate to economies of scope. If two neighboring cities share economic infrastructure or have similar telecommunications demand, costs incurred by a CLEC entrant may be shared between the neighboring markets. As a result, a small or medium-sized city within a large metropolitan area may experience more entry than an otherwise similar city located outside a major urban area. Cities also vary in their population, commercial activity, and other factors that contribute to the demand for CLEC services.

The Regulatory Environment: Individual jurisdictions varied in how the rules in the Telecom Act affected competition between ILECs and local entrants. For example, Mini [2001] carefully documents that CLECs had distinctly different experiences depending on whether they were interconnecting with (1) Regional Bell Operating Companies (RBOCs), (2) GTE (renamed Verizon after its merger), or (3) another independent telecommunications firm. ${ }^{2}$ In addition, state agencies set varying wholesale prices within and across states that affected variable costs of interconnection. Other state regulatory agencies also made it easy or difficult to become a seller or value-added reseller of services, such as those related to offering DSL.

Differentiation: Market analysts have already made considerable strides in providing a taxonomy of potential differentiation strategies (see e.g., NPRG [2000], [2003]). ${ }^{3}$ Our contribution to the literature is in examining whether differences in service offerings affect entry behavior and, if so, by how much. For our purpose, we highlight one specific difference among CLECs, namely, the geographic scope of their offerings. This is an axis of differentiation that correlates with many other differences between firms and appears to be meaningful to employees, employers and regulators. Our goal is to analyze the effects of differentiation for this specific axis; we cannot rule out that heterogeneity within the product types we define or along other axes may also shape entry.

We argue that the distinction between national and local CLECs represents meaningful product differentiation to the extent that customers find the two types of firms to be imperfect substitutes. In Table I, we suggest ways that CLEC services might be tailored to customer needs and why local and national CLECs would potentially differ in the minds of consumers.

\footnotetext{
${ }^{2}$ The RBOCs developed interconnection with entrants as part of a quid-pro-quo with the FCC, which sought to disallow entry into the long-distance market until the RBOCs complied with a series of tests for opening their local markets (Shiman and Rosenwercel [2002]). In contrast, the non-RBOC incumbents simply made interconnection arrangements under the guidance of their local state regulators.

${ }^{3}$ Academic studies and market analysts have highlighted a wide array of ways firms attempted to gain competitive advantages over rivals. For example, some CLECs chose to build their own facilities while others chose to rent from the ILEC at regulated rates and resell their lines to users (perhaps temporarily). As another example, some CLECs enter with a brand name and reputation developed locally in other services, while others enter with a brand name and reputation enhanced by national advertising or an existing distribution and servicing network. See, e.g., Crandall and Sidek, [2001].
}

(C) Blackwell Publishing Ltd. 2006. 
Prices will not fall as quickly with additional entry if customers value the differences enough to pay more to the firm that more closely serves their particular needs. ${ }^{4}$ There may be additional heterogeneity within the local and national categories (correspondence with the characteristics are typical, but not necessary); as such, any finding of differentiation in the broad categories we analyze likely understates its overall importance in this setting. ${ }^{5}$

Product heterogeneity also elicits questions about the asymmetric influence of costs, demand, and the regulatory setting on differentiated CLECs. For example, different components of total market size may provide demand to one type of CLEC over another. Depending on their preferences, regulatory agencies might pass rules that result in lower costs or better opportunities for some CLEC types. It is an open question as to what firms such rules would comparatively favor - local firms with (pre-existing) business or political connections with the state regulator or national firms with larger in-house legal experience in regulatory proceedings.

\section{DATA}

Our modeling approach uses two types of information:

1. Cross-sectional information about CLEC entry. A census of CLEC firms operating in cities across the United States comes from the 1999 and 2002 CLEC Reports, provided by NPRG [2000, 2003].

2. Cross-sectional information about the economic conditions for CLECs at these cities. Market demographics come from the most recent U.S. Census. Various studies of telecommunications regulation provide information about the regulatory environment CLECs face in each location.

\section{III (i). Sample Construction and the Endogenous Variables}

We analyze product differentiation and competition among CLECs by studying the structure of a cross-section of markets. We attempt to

\footnotetext{
${ }^{4}$ In complementary work, Economides, Seim and Viard [2004] find evidence that CLEC customers pay a higher price than necessary given their calling plans and their ex post usage behavior. The authors interpret this as being partially the result of product differentiation among the CLECs - consumers are willing to pay more because they find particular CLECs to have higher quality for them.

${ }^{5}$ For example, local firms differ in whether they focus primarily on customers in dense urban settings or smaller 'rural' settings. Among the rural firms, more than half come with experience in rural telephone service in a nearby area, a form of branding with potential value, but only over a limited geographic range. Many of the national firms focus on urban environments only, but some operate in rural areas as well. Both national and local firms also differ in their bundling strategies, depending on their other lines of business. A small number of national and local CLECs also offer cable television, bundling bills for telephony with the cable bill. For more detail see NPRG [2000, 2003]. While we do not concentrate on it here, exploiting such consequences of heterogeneity may also prove fruitful.
} 


\section{TABLE I}

\section{Product Characteristics Associated with Geographic Differentiation Strategies and Potential Consumer Preferences}

Product Characteristic
Location Coverage:
Footprint of offerings may
be tailored to multi-
establishment users or to
users in small number of
locations.

Menu of Services: Offering a specific combination of services may have value to a targeted group of users.

Service Quality: The CLEC may invest in equipment or maintenance organization for providing after-sale services.

Advanced Data Services: The CLEC may offer data services using many of the same facilities employed for voice services.

Billing: Tailor prices to specific needs of customers.
National CLECs

Example: Offer national footprint

in many major cities and MSAs. ${ }^{*}$

Appeals to: Businesses with multiple establishments and offices in major MSA's

Example: Give one source for all local, long distance and data communication and networking needs.

Appeals to: Geographically diverse business with managers who procure communications services from a single budget. They may need to monitor a standardized operation in many different locations.

Example: Offer guarantees for communications operations over a large geographic area.

Appeals to: Large businesses that do not want to invest in in-house employees for this activity, are trying to manage multiple facilities and face large financial losses if its facilities go down.

Example: Offer Internet access in many places and offer to arrange for data transport between establishments in diverse locations.

Appeals to: Large businesses that may want a standardized set of access points around the country for mobile national work force.

Example: Offer volume discounts for repeated communications between two geographically distant establishments.

Appeals to: Large users with common communications demands between establishments.

\author{
Local CLECS
}

Example: Offer service in local region only.

Appeals to: Users with one or small number of establishments in that geographic region.

Example: Tailor contracts for local, long distance, and data communication and networking needs to the circumstances faced by the business.

Appeals to: Small users that (1) want a single local provider to learn their business needs and adapt to them and (2) do not need many extra services associated with running complex operations over diverse geographic locations.

Example: Offer 24-hour hightouch service over a small geographic area for all networking needs.

Appeals to: Small businesses that do not want to hire an employee for this operation and that want to phone a trusted source that understands the nuances of its local business if/when urgent needs arise.

Example: Offer Internet access at the establishment and arrange for traffic handoff with national ISP. $^{* *}$

Appeals to: Small businesses that want Internet access from known and local provider with a reputation for high-quality services.

Example: Explain many options for billing plans. Give the user options to change frequently.

Appeals to: Local users that want a flexible arrangement so they can change it frequently.

\footnotetext{
${ }^{*}$ MSA = Metropolitan Statistical Area

${ }^{* *}$ ISP $=$ Internet Service Provider

(C) Blackwell Publishing Ltd. 2006.
} 
distinguish between as many different local markets as we can, while taking care to define markets in such a way that the set of firms in the market all compete with each other (at least to some extent) and that no firms outside the defined market are competitors.

For CLECs, the most appropriate geographic market definition is at the level of individual cities. Although jurisdictional boundaries for cities do not always correspond with economic market boundaries in many industries, cities best approximate markets for CLECs. The services CLECs provide are inherently locally focused — the firm must establish a presence in a city in order to connect customers or businesses residing there. This makes most small and medium-sized cities geographically distinct market areas, even when they are suburbs in large metropolitan areas. Indeed, our data indicate that CLECs have chosen to provide service in some cities within particular Metropolitan Statistical Areas (MSAs) and not others. We avoid the potential concern of distinct submarkets within cities because we do not include larger cities in our analysis. ${ }^{6}$

Similarly, the total size of the sample involves some trade-offs. We construct a sample of every city in the United States with at least one actual CLEC entrant in either 1999 or 2002, while dropping a few cities due to incomplete information. To help identify the margin between any CLEC entry and none, we include cities that were candidates for entry but had not yet experienced entry - specifically, every city in which any CLEC expressed any announced plan to enter, even when these plans were several years in the future. Adding these 'planned' CLECs yields an additional set of cities with no actual operating CLECs in either year. Also, this provides us with a convenient stopping rule, since there is little statistical benefit from including each of the thousands of small isolated cities in the United States with little economic base for supporting CLEC entry. ${ }^{7}$ At the other extreme, we drop those cities with very thick CLEC markets, having ten or more total (operating plus planned) CLECs in either 1999 or 2002. Many of these cities experienced CLEC entry prior to the Telecom Act, as documented in research that complements our analysis. ${ }^{8}$

As shown in Table II, our sample construction guidelines generate a total of 1,119 city observations in the data set. Part A of the Table summarizes the

\footnotetext{
${ }^{6}$ This difficulty is most serious in places such as Los Angeles or New York City; for example, some CLECs reported operating in 'New York City' while others said they offered services in 'Manhattan.' From these descriptions, it was impossible to discern whether the firms were competitors. Cities with potentially overlapping submarkets were removed from the final data set.

${ }^{7}$ This does, however, preclude us from estimating a threshold between cities where entry is at least planned and those with no CLEC activity planned at all. This threshold may be of some policy interest also, but it is beyond the scope of this paper.

${ }^{8}$ See Woroch [2001], which documents CLEC entry in the largest U.S. cities in the 1980's and early 1990's. We drop 64 cities based on this criterion. A similar set of cities would be dropped based on an analogous population criterion, but since 'market size' is multidimensional, we preferred this standard for inclusion into the sample.
} 
TABLE II

Histogram of Cities: Number of Operating and Planned CLECs in the MARKET

\begin{tabular}{|c|c|c|c|c|c|c|c|c|}
\hline \multicolumn{9}{|c|}{$\begin{array}{l}\text { A. } 1999 \text { DaTA } \\
\text { Planned }\end{array}$} \\
\hline Operating & 0 & 1 & 2 & 3 & 4 & 5 & $6+$ & Total \\
\hline 0 & 467 & 237 & 17 & 4 & 1 & 0 & 0 & 726 \\
\hline 1 & 202 & 38 & 14 & 5 & 0 & 0 & 1 & 260 \\
\hline 2 & 36 & 21 & 13 & 5 & 2 & 1 & 0 & 78 \\
\hline 3 & 6 & 9 & 10 & 3 & 0 & 0 & 2 & 30 \\
\hline 4 & 4 & 6 & 0 & 2 & 1 & 4 & 0 & 17 \\
\hline 5 & 0 & 1 & 1 & 0 & 2 & 0 & 0 & 4 \\
\hline $6+$ & 0 & 3 & 0 & 1 & 0 & 0 & 0 & 4 \\
\hline Total & 715 & 315 & 55 & 20 & 6 & 5 & 3 & 1,119 \\
\hline \multicolumn{9}{|c|}{$\begin{array}{l}\text { B. } 2002 \text { DaTA } \\
\text { Planned }\end{array}$} \\
\hline Operating & 0 & 1 & 2 & 3 & 4 & 5 & $6+$ & Total \\
\hline 0 & 263 & 54 & 0 & 0 & 0 & 0 & 0 & 317 \\
\hline 1 & 549 & 21 & 2 & 0 & 0 & 0 & 0 & 572 \\
\hline 2 & 102 & 14 & 1 & 0 & 0 & 0 & 0 & 117 \\
\hline 3 & 30 & 12 & 1 & 1 & 0 & 0 & 0 & 44 \\
\hline 4 & 14 & 10 & 1 & 0 & 0 & 0 & 0 & 25 \\
\hline 5 & 11 & 5 & 3 & 1 & 0 & 0 & 0 & 20 \\
\hline $6+$ & 13 & 10 & 1 & 0 & 0 & 0 & 0 & 24 \\
\hline Total & 982 & 126 & 9 & 2 & 0 & 0 & 0 & 1,119 \\
\hline
\end{tabular}

firm counts in 1999. The number in each box indicates the number of cities that have the corresponding number of operating and planned CLECs. Of the 726 cities with no operating CLEC, 467 also had no planned CLECs, which left 259 cities with only a planned CLEC entry. A total of 260 cities had just one firm operating, with the numbers getting smaller through six or more firms operating. In the planned category, there was one planned CLEC in 315 cities (most of these were among the 259 cities with no operating CLECs) and the number of cities with CLECs in the planned category decreases rapidly across the table.

Part B of Table II contains similar data for 2002. It is clear from these data that despite the well-publicized market declines and bankruptcies in the period between 1999 and 2002, there was substantial expansion of the geographic reach of CLEC markets. By 2002, the number of cities with no operating CLEC had reduced to 317 . Of these, there were only 263 cities with also no planned firms. In addition, the number of cities that have at least one operating CLEC had increased to 802. Many of these were cities experiencing new entry between 1999 and 2002, as 572 cities had one operating CLEC in 2002 (compared to 260 cities in 1999). This pattern continues as the number of operating firms increases, as there are more cities in 2002 as we compare each entry in the last column of the two panels. 
TABLE III

Transitions Between I999 Data AND 2002 Data

\begin{tabular}{|c|c|c|c|c|c|}
\hline \multirow{2}{*}{\multicolumn{2}{|c|}{ City Markets in 1999 Data Set }} & \multicolumn{3}{|c|}{ Market Transitions by 2002} & \multirow[b]{2}{*}{ Total } \\
\hline & & $\begin{array}{c}1999 \text { Operating } \\
\text { > } 2002 \text { Operating }\end{array}$ & $\begin{array}{l}1999 \text { Operating } \\
=2002 \text { Operating }\end{array}$ & $\begin{array}{l}1999 \text { Operating } \\
<2002 \text { Operating }\end{array}$ & \\
\hline Zero Operating & Zero Planned & - & 36 & 431 & 467 \\
\hline & $1+$ Planned & - & 173 & 86 & 259 \\
\hline 1 Operating & & 96 & 102 & 62 & 260 \\
\hline 2 Operating & & 27 & 22 & 29 & 78 \\
\hline 3 Operating & & 7 & 7 & 16 & 30 \\
\hline 4 Operating & & 6 & 1 & 10 & 17 \\
\hline 5 Operating & & 0 & 1 & 3 & 4 \\
\hline $6+$ Operating & & 2 & 1 & 0 & 4 \\
\hline Total & & 138 & 343 & 638 & 1,119 \\
\hline
\end{tabular}

Table III contains the raw data related to the CLEC market transitions between 1999 and 2002. The rows indicate the number of operating firms as of 1999 and the columns represent the transitions. For example, for the 78 cities with two operating CLECs in 1999, 22 had exactly two operating in 2002 as well, 27 had fewer and 29 had more. There is substantial movement in both directions - particularly considering the entry into and exit from the data set. These tallies do suggest that any inference made about a single cross-section would be more convincing to the extent that it were true in both time periods. While much of our analysis will focus on each cross-section separately, we will also attempt to find explanations for the market structure transitions between 1999 and 2002.

To study differentiation among CLECs, we classify firms into discrete categories on the basis of how they vary in the geographic extent of their operations. ${ }^{9}$ As was previously discussed, product characteristics associated with a CLEC's geographic footprint may attract different types of customers. ${ }^{10}$ The NPRG data lists the complete set of cities into which each CLEC has entered. We classify CLECs as local/regional if the geographic range of cities in which they operate is within a few adjacent

\footnotetext{
${ }^{9}$ Our earlier draft also explored differences between firms focused exclusively on business and those serving both on business and residential customers. Our findings for the local/ national differences were stronger, so we highlight those below. We also investigated differences between those who also offer cable services and those who do not, but (in contrast to the attention it generated in the popular press) found such a strategy in less than 10 per cent of the CLECs studied. This was insufficient variation to generate any inferences.

${ }^{10}$ We investigated differences in the strategies among local firms, with some focusing mostly on urban environments and others on rural environments. A high fraction of the latter had experience in providing telephony in regions near those where they entered. We inquired whether this heterogeneity among local CLECs was correlated with entry behavior vis-à-vis national CLECs, and found no large differences (except for the practically tautological point that local rural CLECs are in small towns and not large metro areas), so we do not highlight this below.
} 
TABLE IV

Number of National and LOCAL/REgional CLECs PER City

\begin{tabular}{|c|c|c|c|c|c|}
\hline \multicolumn{6}{|c|}{$\begin{array}{l}\text { A. } 1999 \text { DATA } \\
\text { National CLECs }\end{array}$} \\
\hline $\begin{array}{l}\text { Local/Regional CLECs } \\
0 \\
1 \\
2 \\
3+ \\
\text { Total }\end{array}$ & $\begin{array}{r}0 \\
726 \\
197 \\
38 \\
15 \\
976\end{array}$ & $\begin{array}{r}1 \\
63 \\
35 \\
9 \\
7 \\
114\end{array}$ & $\begin{array}{r}2 \\
5 \\
9 \\
6 \\
5 \\
25\end{array}$ & $\begin{array}{l}3+ \\
2 \\
2 \\
0 \\
0 \\
4\end{array}$ & $\begin{array}{r}\text { Total } \\
796 \\
243 \\
53 \\
27 \\
1,119\end{array}$ \\
\hline \multicolumn{6}{|c|}{$\begin{array}{l}\text { B. } 2002 \text { DATA } \\
\text { National CLECs }\end{array}$} \\
\hline $\begin{array}{l}\text { Local/Regional CLECs } \\
0 \\
1 \\
2 \\
3+ \\
\text { Total }\end{array}$ & $\begin{array}{r}0 \\
317 \\
279 \\
18 \\
12 \\
626\end{array}$ & $\begin{array}{r}1 \\
293 \\
55 \\
11 \\
8 \\
367\end{array}$ & $\begin{array}{r}2 \\
43 \\
18 \\
8 \\
2 \\
71\end{array}$ & $\begin{array}{l}3+ \\
10 \\
18 \\
16 \\
11 \\
55\end{array}$ & $\begin{array}{r}\text { Total } \\
663 \\
370 \\
53 \\
33 \\
1,119\end{array}$ \\
\hline
\end{tabular}

states. Those operating in cities from multiple regions of the country are labeled national. ${ }^{11}$

In Table IV, we present the breakdown between the national and the local/ regional CLECs across the individual markets in the data set. Here we see that the cities with fewer operating CLEC's in 1999 typically contain predominately local/regional firms - for example, among the markets with one operating firm, that firm is a local/regional CLEC in about $75 \%$ of the cases. By 2002, there is more balance, as slightly more than half of the oneCLEC cities have a national as their single firm. As the total number of CLECs per city increases the tendency for cities to be differentiated is represented by the share of the data in the interior of the table. For example, nearly half of the two-CLEC markets have one local/regional firm and one national firm in both years. ${ }^{12}$ This general pattern continues in markets with

\footnotetext{
${ }^{11}$ For the 2002 data, for example, we classify two-thirds (74) of the 111 CLECs in the NPRG data as local/regional and one-third (37) as national. More than two thirds of the local/regional CLECs operate either within a single state (37) or in two or three adjacent states (13). The remainder of the CLECs classified as local/regional operate in between four and ten states; such CLECs are only classified as local/regional if the set of states in which they operate are contiguous. A few of the CLECs classified as national (7) operate in a small number of states, but in different regions of the country. The other national CLECs (30) reported widespread operations in more than ten states. The definitions for local/regional and national are similar in the 1999 data. Note that national firms are much more likely to be larger publicly traded firms whose plans may have been influenced by the crash of the stock market bubble after 1999 .

${ }^{12}$ Specifically, note that two tosses of a fair coin should show one tail and one head half the time. Intuitively, our econometric model identifies additional differentiation from the raw data by isolating markets (based on their characteristics) where the entry of one CLEC type or the other is more common. Section IV (iii) provides additional details on identification and testing. 
three or four CLECs as well. While these data by themselves only hint at the importance of differentiation, our econometric model will allow us to tease out market-level demand and cost explanations for the observed entry patterns. In so doing, we will be able to identify how competition influences entry, distinguishing between local and national CLECs' competitive effects.

\section{III (ii). Economic Data about Localities}

Cities will differ in their ability to generate the necessary demand to make CLEC entry attractive. To account for these differences, we collected demographic data from each city. Market size was the most important of these characteristics - here, we are interested in both the resident population and measures of business activity, since CLEC services are often particularly valuable to business customers. Population is each city's population and per capita income represents the average income of the city's residents. The variable payroll measures the annual payroll of workers employed in the city; as such it combines both the overall level of business activity and the wages earned by workers. Summary statistics for all of the explanatory variables are included in Table V. Note that we obtained data for these demographic variables from the 2000 Census. Annual data are not available at the level of individual cities, and we would not expect the yearon-year changes in these variables to be large enough to appreciably affect entry decisions.

As was previously described, we hypothesize that CLECs may be able to share costs (such as marketing, administration, and initial costs associated with interconnection) among nearby cities (even if separate facilities are built). It is possible, therefore, that a small city within a larger MSA may be less expensive for a firm to serve than a more isolated city of equal size. We include the dummy variable city in a top-ten $M S A$ to represent those cities that are within the boundaries of one of the ten largest urban areas in the United States. $^{13}$

We also examine differences across cities in the local regulatory environment. Abel and Clements' [2001] study provides us with a

\footnotetext{
${ }^{13}$ We confirm that the dummies were plausibly related to our proposed interpretation of scope economies by noting that CLECs typically also operated in the central city of the suburbs they entered. Of the 381 CLEC observations within a top-ten MSA as of 1999, 333 of them also operated in the MSA's corresponding central city. We explored demographic variables related to density as well. Because facilities-based CLECs must make capital investments in equipment to link their customers, cities with more geographically concentrated residential neighborhoods and business centers may provide CLECs with customers that are less expensive to serve. However, the density measures that we calculated (both residential and for businesses) did not provide additional explanatory power. It may be that density differences affect where CLECs operate within cities but not entry decisions across cities.
} 
TABLEV

EXPLANATORY VARIABLES - Summary STATISTICS

\begin{tabular}{lrc}
\hline Variable & Mean & Standard Deviation \\
\hline Population & 66,429 & 82,320 \\
Payroll & 857,748 & $1,127,046$ \\
Per Capita Income & 22,780 & 9,280 \\
City in Top-Ten MSA & 0.235 & 0.424 \\
Incumbent = RBOC & 0.753 & 0.431 \\
Regulatory Stringency & 1.161 & 0.675 \\
UNE-Loop Rate (Early) & 17.44 & 8.76 \\
UNE-Loop Rate (Late) & 15.08 & 5.85 \\
\hline
\end{tabular}

time-series of regulatory rules that states have used on ILECs under their jurisdiction. ${ }^{14}$ For each state/ILEC combination, we counted the number of years (through 2000) that either a rate freeze or price cap had been imposed (these began to appear in the late 1980's). Our summary measure of regulatory stringency is a collapsed version of this year count - regulatory stringency equals 0 in areas where these alternatives had never been used, 1 if they had been tried for between one and four years, and 2 if a freeze or cap was in place for more than five years. We hypothesize that a higher value of regulatory stringency indicates a regulatory environment in which there is a friendlier attitude toward experimenting with competition with the ILEC. This would translate into lower costs to an entering CLEC.

Specific provisions in the Telecom Act require incumbents to provide interconnection access to CLEC competitors; however, RBOC firms that wanted to enter the market for long-distance services were precluded from doing so until regulators were satisfied that they had been sufficiently cooperative with CLECs' attempting to interconnect and provide service in their local areas. Incumbents that were not RBOC's did not have this incentive to facilitate CLEC entry. Following on the results of Mini [2001], we include an RBOC dummy variable, incumbent $=R B O C$, to control for the differing incumbent incentives vis-à-vis CLECs across the markets.

Finally, local regulators prescribed the costs that CLECs were required to pay for access to the ILEC's infrastructure that was necessary for CLECs to provide service. Depending on the manner in which the CLECs operated, they would need different pieces of the ILEC's network; regulators responded by setting separate piece-by-piece prices for so-called Unbundled Network Elements (UNEs). In many states, regulators experimented with UNE rates over this period; as a result, this is the one explanatory variable

\footnotetext{
${ }^{14}$ Regulators often have different rules for each incumbent carrier within its state. These rules apply to all the areas within that state where the particular incumbent operates. Therefore, it was necessary to match each market to both its incumbent and its state regulator to determine the status of the incumbent competitor.
}

(C) Blackwell Publishing Ltd. 2006. 
for which we use different values in each year's analysis. ${ }^{15}$ Specifically, we use the UNE-Loop rate, as this is the one UNE rate that is typically geographically de-averaged within states. The UNE-Loop rate is usually set lower in more densely populated areas, telling us how costs may differ for CLECs on a city-level basis. ${ }^{16}$ Our choice to employ this rate differs from other studies that have looked at entry and operational differentiation (facilities-based vs. resale). ${ }^{17}$

\section{EMPIRICAL MODELS OF CLEC ENTRY}

The empirical modeling approach we utilize fits into the series of 'multipleagent qualitative-response' frameworks introduced into industrial organization to evaluate entry strategies and market competition. Using a cross-section of markets as data, the econometrician infers the economic factors that contribute to the generation of the observed market structure. Firms' strategies can be represented by discrete decisions (e.g., enter/do not enter a particular market) that are made by evaluating the potential alternatives. Estimation is complicated by the fact that the decisions of competing firms may affect the returns to potential alternatives - for example, entry may be less attractive if other firms also have entered the market. A game-theoretic behavioral model is used to infer the factors influencing individual firm decisions from an observed market structure outcome, which is determined by the choices made by interacting agents.

\section{IV (i). Entry Models Assuming Homogeneity}

Much of the industrial organization literature, as well as previous empirical papers on CLEC entry, have estimated straightforward limited dependent variable models of market structure. These studies typically estimate ordered probits with the number of firms as the dependent variable. The market factors that determine entry are inferred from a profit function that underlies the entry decision, such as

$$
\pi_{m}=X_{m} \beta+Z_{m} \gamma+N_{m} \theta+\varepsilon_{m},
$$

\footnotetext{
${ }^{15}$ A biannual survey by Gregg [2001, 2003] was used to determine the UNE rates over time. The survey's initial release was not until early 2001-this is the best proxy we can use for the 1999 data. For the 2002 sample, we use the January 2003 release. Approximately 60 per cent of the UNE rates were altered over this period.

${ }^{16}$ In Gregg's survey dated January, 2003, the variance across the fifty states in the lowest rate (\$15.77) is only slightly higher than the average difference between the lowest and highest rates (\$15.15). The UNE-Loop rate is used as a proxy for CLEC costs in other studies, including Crandall, Ingraham and Singer's [2004]. The density zones used for geographic de-averaging vary by state; data were matched to cities in the data set with help from Rosston and Wimmer [2001] and by inspection of ILEC websites.

${ }^{17}$ See, e.g., Wood, Zarakas and Sappington [2004] or Jamison [2004] for further discussion about different types of UNE rates in urban areas.
} 
where $m$ denotes the geographic market in question. Markets may differ in the cross-section in $X$-characteristics affecting demand for the firms' products or in $Z$-characteristics that affect the firms' market-specific costs. $N_{m}$ represents the number of firms that have entered the market; $\theta$ indicates the extent to which additional market participants make entry less attractive. The $\varepsilon_{m}$ term represents the components of firm profits that are unobserved to the econometrician. The parameters of this function can be estimated using a cross-section of market structure observations. For example, we may observe two firms operating in market $m$. This implies the following two inequalities in market $m$ :

$$
\begin{aligned}
& \pi_{m}=X_{m} \beta+Z_{m} \gamma+(2)^{*} \theta+\varepsilon_{m}>0 \text { and } \\
& \pi_{m}=X_{m} \beta+Z_{m} \gamma+(3)^{*} \theta+\varepsilon_{m}<0
\end{aligned}
$$

The parameters are determined by maximizing the likelihood that the inequalities implied by the observed market structures (assuming a distribution for the market level error term) hold. The parameter values describe the relative importance of demand, cost and competitive factors in determining counts of operating firms.

\section{IV (ii). Extensions to Heterogeneous Markets}

This approach can be extended to analyze firms in heterogeneous markets as well. Suppose that each market could have firms of two types, label them $A$ and $B$. Now, market structure is represented by an ordered pair $\left(\mathrm{N}_{\mathrm{A}}, \mathrm{N}_{\mathrm{B}}\right)$, which indicates the number of observed firms of each type. Correspondingly, there will be type-specific profit functions for these firms:

$$
\pi_{T m}=X_{m} \beta_{T}+Z_{m} \gamma_{T}+N_{T m} \theta_{T}+N_{-T m} \theta_{-T}+\varepsilon_{T m},
$$

reflecting the fact that the costs, demand, and the unobservables may differ for firms of each type. Furthermore, we can allow the effects of competitors to vary on the basis of whether they offer the same or different product types. $N_{T m}$ indicates the number of same-type firms in the market, and $N_{-T m}$ is the number of firms of the other type. Therefore, the difference between the estimated $\theta_{T}$ and $\theta-_{T}$ parameters captures the extent to which product differentiation may limit the effects of additional competitors on firm entry of each type. A market observed with a structure of $(A, B)$ implies that the following inequalities hold:

$$
\begin{array}{lll}
\pi_{A}(A, B)>0 & \pi_{A}(A+1, B)<0 & \pi_{A}(A, B)>\pi_{B}(A-1, B+1) \\
\pi_{B}(A, B)>0 & \pi_{B}(A, B+1)<0 & \pi_{B}(A, B)>\pi_{A}(A+1, B-1)
\end{array}
$$

To proceed in the case of CLECs, we need to make some assumptions about the nature of the entry process that ultimately generates the market structure outcomes we observe. We start by assuming that there are two possible types of CLECs that could operate in a given market - local/regional firms (L) and 
national firms (N). ${ }^{18}$ CLECs that do enter market $m$ earn $\pi_{T m}(L, N)$, where $T$ is the CLEC type and the ordered pair $(L, N)$ represents the number and product types of all the competitors that also operate in market $m$. We treat entry decisions as being made by each firm on a market-by-market basis, though we do permit indirect spillovers by including proximity to large cities as a factor in whether particular markets are more attractive. Beyond this, however, we cannot address the possibility of multimarket effects given this setup. ${ }^{19}$

Unfortunately, without some additional structure on the entry process, multiple equilibria corresponding to the above set of inequalities are possible. To make estimation feasible, we assume that the observed outcome is arrived at as if the potential entrants were playing a Stackelberg game, with the most profitable type firms moving first. Since firms within each type are identical, entry is determined at each stage by comparing whether the next local firm is more or less profitable than the next national firm, anticipating that potential competitors will subsequently make optimal decisions once the earlier movers have committed to their choice. ${ }^{20}$ The outcome of this Stackelberg game has the attractive feature of being observationally equivalent to the outcome in a repeated simultaneous move entry/exit game, where the later entry of a higher profit type would likely precipitate the subsequent exit of a competitor that is no longer profitable as a result of the entry. ${ }^{21}$ This assumes that our observations represent something resembling a long-run equilibrium; so it will be quite informative to explore the impact of this modeling choice by comparing the results in two separate time periods. ${ }^{22}$

\footnotetext{
${ }^{18}$ Of course, in this context the ILEC is always present and generates a potential competitive effect that could vary depending on its characteristics and on CLEC type. However, since ILEC presence is exogenous, we do not consider it within the context of the entry game. Instead, we can determine its competitive effect by including it among the market characteristics, as described in the previous section.

${ }^{19}$ Fortunately, our data suggest multimarket effects will not be a very serious concern in this case. While national firms must have entered into multiple cities by construction, the particular group of cities they enter is not prescribed. In particular, national firms typically only enter a subset of the cities within a given MSA, even after entering the MSA's central city. For an alternative empirical approach that can accommodate such spillovers directly (in certain contexts), see Bajari and Fox [2005].

${ }^{20} \mathrm{~A}$ natural alternative is a simultaneous move game; however, it has been well established that such a game has multiple equilibria, which precludes straightforward econometric estimation (see Tamer [2003]). We proceed with the Stackelberg assumption, in part relying on the finding in Mazzeo [2002] that parameter estimates are very similar across various game formulations that generate unique equilibria.

${ }^{21}$ Long-run, dynamic equilibrium models of entry and exit have been proposed, but have not yet been successfully estimated. See Pakes [2003] for a discussion of recent progress in this area.

${ }^{22}$ As long as we assume that an additional market participant always decreases profits and that the decrease is larger if the market participant is of the same product type, a unique equilibrium exists under the Stackelberg assumption (Mazzeo [2002] contains proofs of existence and uniqueness). Since the equilibrium is unique, the sum of the probabilities for all market configurations always equals one. Note that the ordered pair represents the product types of competing firms (not including itself). For example, for a local CLEC in market (L,N), the relevant ordered pair is $(\mathrm{L}-1, \mathrm{~N})$; for a national CLEC, it is $(\mathrm{L}, \mathrm{N}-1)$.
} 
Under the specification described above, the inequalities corresponding to exactly one of the possible ordered-pair market structure outcomes are satisfied for every possible realization of $\left(\varepsilon_{\mathrm{L}}, \varepsilon_{\mathrm{N}}\right)$ based on the data for the market in question and values for the profit function parameters. We assume an independent, bivariate standard normal distribution for the error term, and a predicted probability for each of the possible outcomes is calculated by integrating $f\left(\varepsilon_{\mathrm{L}}, \varepsilon_{\mathrm{N}}\right)$ over the region of the $\left\{\varepsilon_{\mathrm{L}}, \varepsilon_{\mathrm{N}},\right\}$ space corresponding to that outcome. Maximum likelihood selects the profit function parameters that maximize the probability of the observed market configurations across the dataset. The likelihood function is:

$$
L=\prod_{m=1}^{M} \operatorname{Prob}\left[(L, N)_{m}^{O}\right]
$$

where $(L, N)_{m}^{O}$ is the observed configuration of firms in market $m$ - its probability is determined by the inequalities implied by the assumptions governing entry, as well as the the parameters and the data for market $m$. For example, if $(L, N)^{O}=(1,1)$ for market $m$, the contribution to the likelihood function for market $m$ is Prob $[(1,1)]$.

\section{IV (iii). Identification and Testing}

This approach is best suited for analysis of small and medium-sized cities, because where there are many firms, the marginal effect of additional competitors is likely to be very small. Consequently, we focus on measuring the key differences between cities that may become substantially more competitive with additional entry - places such as Duluth, Little Rock, and Fresno. We believe that for policy purposes, these markets are quite interesting. Moreover, the costs of dropping a few larger cities from our data set are small. As discussed in Section III, other studies (such as Woroch [2001]) have found that the largest cities will be very competitive no matter what the regulations for CLECs are.

Identification of the parameters representing competitive effects comes from comparing otherwise similar markets with different structures or, conversely, different markets with otherwise similar structures. The estimated $\beta$ and $\gamma$-parameters help to make markets more 'similar,' as they account for exogenous characteristics that make entry of CLECs (and of particular CLEC types) more attractive. Controlling for market characteristics allows us to identify the $\theta$-parameters describing competition and make inferences beyond what one could infer from comparisons with random assignment in the raw data from Table IV. In turn, the differentiated competition parameters are identified by comparing market characteristics and observed differentiation patterns in markets with the same number of firms. 
Finally, it is appropriate to think of our classification as a maintained assumption. Our null hypothesis is that firms enter without regard to the product type of their competitors; if we fail to reject the null hypothesis, we do so either because firms do not differentiate from their within-market competitors or because we have inappropriately classified the dimensions on which they differentiate. If we reject the null hypothesis, then we accept the alternative hypothesis that CLECs enter cities in such a way as to differentiate along the dimensions we classify. ${ }^{23}$

\section{EMPIRICAL RESULTS}

To provide a comparison with earlier work, we begin our empirical analysis by estimating ordered probits whose dependent variables are the numbers of operating CLECs. This is important because, in addition to incorporating differentiation into our analysis, we utilize a different dataset. While prior CLEC entry studies used FCC data and defined LATAs as the unit of observation, we examine city-level markets using data from NPRG (each LATA may contain several individual city markets, as defined in our dataset). We would hope that a similar empirical analysis would yield qualitatively similar results, with additional insight about the precise relationship between local economic factors and entry levels. These estimates also provide a useful benchmark against our later estimates that account for differentiation and allow us to explore the effect of differentiation on market evolution. ${ }^{24}$

\section{V (i). Benchmark Results: Homogeneous Products}

In Table VI, we present the results from two ordered probit estimations one each for 1999 and 2002. The dependent variable is a count of the number of CLECs doing business in the city for each year. Recall that we pool the data from the two years to constitute the sample, so that cities with zero entrants in 1999 include both the cities that have at least one planned entrant in 1999 as well as those cities that do not have an actual or planned entrant until 2002.

Starting with the 1999 results, we see that population and the business variable, payroll, are positively correlated with CLEC entry, but the

\footnotetext{
${ }^{23}$ Consistent with our earlier remarks about the potential presence of multiple axes of differentiation, to the extent that we reject the homogenous-competitor hypothesis here, we are likely to have a conservative estimate of the total market differentiation when ILECs are considered as well.

${ }^{24}$ While the ordered probit estimated below assumes homogeneity in terms of competitive effects, the econometric model described in the previous section does not reduce to an ordered probit if the same and cross-type competitive effects are constrained to be equal (since the effect of the control variables and unobservables vary by type). As such, these results are useful primarily for benchmarking purposes.
} 
TABLEVI

Ordered Probits of CLEC Firm Counts

\begin{tabular}{|c|c|c|c|c|c|c|}
\hline & \multicolumn{3}{|c|}{ A. 1999 DATA } & \multicolumn{3}{|c|}{ B. 2002 DATA } \\
\hline & Coefficient & Standard Error & $\mathrm{Z}$ & Coefficient & Standard Error & $\mathrm{Z}$ \\
\hline Population & $2.72 \mathrm{e}-6$ & $6.51 e-7$ & 4.18 & $2.83 e-6$ & $6.29 \mathrm{e}-7$ & 4.50 \\
\hline Payroll & $4.05 \mathrm{e}-7$ & $5.01 \mathrm{e}-8$ & 8.08 & $3.65 \mathrm{e}-7$ & $4.81 \mathrm{e}-8$ & 7.60 \\
\hline Per Capita Income & $-1.11 \mathrm{e}-5$ & $4.91 \mathrm{e}-6$ & -2.26 & $2.61 \mathrm{e}-6$ & $4.05 e-6$ & 0.64 \\
\hline City in Top-Ten MSA & 0.283 & 0.095 & 2.97 & -0.250 & 0.089 & -2.82 \\
\hline Incumbent $=\mathrm{RBOC}$ & -0.050 & 0.092 & -0.55 & 0.330 & 0.083 & 3.97 \\
\hline Regulatory Stringency & 0.130 & 0.060 & 2.17 & 0.889 & 0.053 & 1.68 \\
\hline UNE-Loop Rate & -0.025 & 0.007 & -3.78 & -0.017 & 0.007 & -2.32 \\
\hline Number of Observations & & 1,119 & & & 1,119 & \\
\hline Psuedo- $\mathrm{R}^{2}$ & & 0.1713 & & & 0.1229 & \\
\hline
\end{tabular}

Note: The dependent variable comes from the last column in each panel of Table III. All of the explanatory variables are the same value in both estimations, except for the UNE-Loop rate.

residential variable, per capita income is not. These results are certainly consistent with the idea that initially CLECs were demanded more by business customers; in fact, CLECs may be an inferior good as far as local residential communications is concerned. We also find some evidence for geographic scope economies, as the dummy variable (city in a top-ten MSA) is positive and significant: in 1999, for an otherwise similar city, more CLEC entry occurred if the city was a suburb of a major city than if it were in an outlying location. The remaining parameter estimates relate to the regulatory variables. Contrary to expectations, additional CLEC entry was not more likely in areas where the incumbent firms were RBOCs despite the potential benefit associated with facilitating competition in their service territories. The other regulatory variables did predict entry as expected, with more firms entering in cities where regulators had experimented with nontraditional forms of regulation for a longer period of time. In addition, the effects of the costs of interconnection were significant, as more CLECs were present in 1999 in cities where the UNELoop rate was lower. This result suggests the role that policy makers can play in inducing CLEC entry - a ten percent reduction in the UNE-Loop rate (from the mean) reduced the population needed to support an additional CLEC by nearly $16,000 .{ }^{25}$

The results for the 2002 ordered probit indicate that the effect of most of the explanatory variables are the same as in 1999, with more CLECs entering cities with higher populations, with more business activity and in states with more friendly regulators and lower interconnection costs. The effect of per capita income is not statistically different from zero in 2002. There are two major differences in the analyses, however, both of which are striking. First, CLECs appear to have changed their strategy regarding entering in suburbs

\footnotetext{
${ }^{25} \mathrm{Using}$ the data from Table $\mathrm{V}$ along with the estimates from Table VI, we compute: $(0.025)^{*}(1.74) /(2.72 \mathrm{e}-6)=15,993$. 
of metropolitan areas, as the effect of the MSA dummy is now negative. Thus, CLEC entry occurs in cities in an outlying location just as often, if not more often, than in cities in a top-ten MSA. Additionally, entry had by 2002 responded as legislators had hoped with respect to the incentives for RBOCs to facilitate competitive entry. The positive and significant sign on the RBOC dummy indicates more CLEC activity in an otherwise similar city whose incumbent is an RBOC.

\section{V (ii). Product Heterogeneity Estimates}

In the heterogeneous products analysis, we allow for up to three firms of each product type in the market - therefore, the endogenous market structure variable can take on one of sixteen possible values. The information in Table IV captures the variation in the dependent variable across all the markets in the data set. ${ }^{26}$ For each firm type and market configuration, a set of dummy variables is defined, and the corresponding $\theta$-parameters represent the incremental effects of additional competitors on the profits of firms in the market:

$\theta_{L L 1}=$ effect of first local/regional competitor on local/regional CLECs, $\theta_{L L 2}=$ effect of second local/regional competitor on local/regional CLECS,

$\theta_{L N 1}=$ effect of first national competitor on local/regional CLECs,

$\theta_{L N 2}=$ effect of second national competitor on local/regional CLECs,

$\theta_{L N 3}=$ effect of third national competitors on local/regional CLECs,

$\theta_{N N 1}=$ effect of first national competitor on national CLECs,

$\theta_{N N 2}=$ effect of second national competitor on national CLECs,

$\theta_{N L 1}=$ effect of first local/regional competitors on national CLECs,

$\theta_{N L 2}=$ effect of second local/regional competitors on national CLECs, and

$\theta_{N L 3}=$ effect of third local/regional competitors on national CLECs

The estimated parameters can be used to evaluate the null hypothesis of homogeneous competition. A strict test of that property is $\left|\theta_{L L 1}\right|$ $=\left|\theta_{L N 1}\right|$ and $\left|\theta_{N N 1}\right|=\left|\theta_{N L 1}\right|$. We can reject the null in favor of a model of differentiated competition if we find $\left|\theta_{L L 1}\right|>\left|\theta_{L N 1}\right|$ and $\left|\theta_{N N 1}\right|>\left|\theta_{N L 1}\right|$. Notice that in the absence of within-type heterogeneity, we would expect to find $\left|\theta_{L L 1}\right|>\left|\theta_{L L 2}\right|$ and $\left|\theta_{N N 1}\right|>\left|\theta_{N N 2}\right|$, etc.

As in the probit estimations, the appropriate $X$-variables to include are either correlated with CLEC demand or entry costs in each market. The

\footnotetext{
${ }^{26}$ For example, there are eleven markets whose dependent variable is $(2,1)$ in the 2002 data - two local operating CLECs and one national operating CLEC (Part B, Table IV). Cities with more than three firms in either category are treated as if they have exactly three in that category.
} 
specification also allows the effects associated with the $X$-variables to vary by product type. To ease estimation, the data for the $X$-variables are transformed to the log of the actual value for that market divided by the sample mean of that $X$-variable across all the markets in the data set. Consequently, a value of $X$ equal to the sample mean becomes zero, a value above the mean becomes positive and a value below the mean becomes negative. ${ }^{27}$ This also eases interpretation because it puts all variables on the same scale and allows for a quick comparison of the economic importance of competing variables. For example, we can say that differentiation is 'economically important' if its effect on entry is as large as the effect of variance in other exogenous variables, such as city population and payroll, which are known to shape the number of overall entrants.

We present the results from the heterogeneous products analysis below and in Table VII. The estimated parameters indicate the impact on entry of each type of CLEC depending on market conditions and the competitors they face. For example, the constants indicate the baseline attractiveness of entry for each type. Each of the constants is below zero in Part A of Table VII (because so many of the markets have no entrants as of 1999), but the relative value of the constants indicates that, all else being equal, a local/regional CLEC would be more likely to enter before a national CLEC, since $C_{L}=-0.4250>C_{N}=-0.7525 .{ }^{28}$ These estimates reflect the entry data from Part A, Table IV, where entry is weighted toward the local/regional firms. Since population and payroll have positive coefficients, larger values of these variables will offset the negative constants and predict entry. The relative size of these coefficients will affect the predicted product-type configurations.

For example, consider the population variable - the parameter estimate for both product types is positive, which indicates that larger cities attract more CLECs of either type. However, the estimated parameter is higher for the national CLECs than for the local/regional CLECs. This indicates that as the population in a city increases, the relative attractiveness of entry for national CLECs increases as well. To illustrate how this can change market structure, suppose that in market $m$, the population is 3.5 times the sample mean. In addition, suppose that city in a top-ten MSA, RBOC and regulatory stringency are all set to zero, and the other $X$-variables are at their sample means. With no competitors, operating a national CLEC is

\footnotetext{
${ }^{27}$ The transformation is done solely to facilitate estimation of the model. The estimation routine converges more easily if the ranges of the independent variables are similar to each other.

${ }^{28}$ All the figures presented in this section represent predicted values. The comparisons between product types assume that values of the unobservables for both types are at their mean - zero. Directly evaluating the probability that one type's entry is more likely than the other's requires the standard errors of the parameters, as well as an assumption about the variance of the errors for each type.
} 
now feasible and more attractive $\left[\pi_{N}=-0.7525+(1.25)^{*}(0.6312)=0.036\right]$ than operating a local/regional CLEC $\left[\pi_{L}=-0.4250+(1.25)^{*}(0.2571)\right.$ $=-0.103]{ }^{29}$ As the value of each explanatory variable changes, entry becomes more or less attractive depending on the sign of the coefficient; and the more attractive product type will depend on the relative value of the coefficients. While the effects of the explanatory variables are relatively similar across types in 1999, it is interesting to note the strikingly different responsiveness of the two types to the interconnection rates in 1999.

The key result in Table VII comes from the estimated competitive effects on CLEC type, as captured by the $\theta$-parameters. The estimates indicate that the effects of competitors come predominately from same-type CLECs. We observe that the presence of the first similar competitor makes entry unattractive $\left(\theta_{L L I}=-1.02 ; \theta_{N N I}=-0.98\right)$ as compared to the presence of the first competitor of the other product type $\left(\theta_{L N I}\right.$ and $\left.\theta_{N L I}\right)$, which are estimated to be very close to zero. In addition, the second same-type competitor has a comparatively smaller effect than the first for both the local $/$ regional $\left(\theta_{L L 1}=-1.0155<\theta_{L L 2}=-0.6606\right)$ and national $\left(\theta_{N N 1}=\right.$ $\left.-0.9810<\theta_{N N 2}=-0.8007\right)$ CLECs. Lower margins typically result from lower market concentration; however, differentiating on the basis of geographic footprint appears to insulate CLECs from the effects of additional competitors. In fact, comparing the values of the $\theta$ and $\beta$ parameters gives an idea of the market size trade-offs associated with product differentiation. A considerably larger market - more than a standard deviation above the mean of the two main market size variables, population and payroll - is needed to offset the effect of the first additional same-type competitor on a national CLEC's returns, for example. ${ }^{30}$

To assess the robustness of these findings to the recent industry upheaval, we performed the same analysis on the 2002 data, with the parameter estimates in Part B of Table VII. Notice first that the value of the constants is larger (since fewer cities have zero firms by 2002) and that their relative value is now skewed toward the national CLECs (mirroring Part B, Table IV). Most important, the patterns of the $\theta$ parameters have remained quite similar. Namely, the effect of the first same-type firms is roughly double that of the second same-type firm, while the effects of different-type competitors are relatively negligible in all but one case. The estimated $\theta_{L N I}$ coefficient for 2002 is equal to -0.4244 , still substantially below the corresponding same-

\footnotetext{
${ }^{29}$ With population 3.5 times the sample mean, the parameter estimate for income is multiplied by $\ln (3.5)=(1.25)$ to compute the prediction. Given the population data from Table $\mathrm{V}$, a value of population 3.5 times the sample mean corresponds to two standard deviations above the mean. The transformed value of an $X$-variable at its sample mean is zero; therefore, the other variables do not contribute to the prediction.

${ }^{30}$ Using the data from Table V and VII, the absolute value of the relevant $\theta$ coefficient $(0.981)$ and the sum of the two $\beta$ coefficients times $X$-values of 1.6 standard deviations above the mean for population and payroll: $\left|(1.093)^{*}(0.6312)+(1.132)^{*}(0.2603)\right|=(0.985)$ are roughly equal. 
TABLEVII

Heterogeneous Products Model

\begin{tabular}{|c|c|c|c|c|c|}
\hline \multirow[b]{2}{*}{ Parameter } & & \multicolumn{2}{|c|}{ A. 1999 Data } & \multicolumn{2}{|c|}{ B. 2002 Data } \\
\hline & & Coefficient & $\begin{array}{l}\text { Standard } \\
\text { Error }\end{array}$ & Coefficient & $\begin{array}{c}\text { Standard } \\
\text { Error }\end{array}$ \\
\hline \multicolumn{6}{|l|}{ Effect on Local/Regional CLECs } \\
\hline Constant & $\mathrm{C}_{\mathrm{L}}$ & -0.4250 & 0.1170 & 0.1165 & 0.1140 \\
\hline Local/Regional Competitor \#1 & $\theta_{\mathrm{LL} 1}$ & -1.0155 & 0.0590 & -1.1903 & 0.0567 \\
\hline Local/Regional Competitor \#2 & $\theta_{\mathrm{LL} 2}$ & -0.6606 & 0.0733 & -0.4834 & 0.0585 \\
\hline National Competitor \#1 & $\theta_{\mathrm{LN} 1}$ & $-1.11 \mathrm{e}-5$ & 0.0006 & -0.4244 & 0.0745 \\
\hline National Competitor \#2 & $\theta_{\mathrm{LN} 2}$ & $-7.56 \mathrm{e}-6$ & 0.0004 & $-7.06 \mathrm{e}-6$ & 0.0003 \\
\hline National Competitor \#3 & $\theta_{\mathrm{LN} 3}$ & $-1.10 \mathrm{e}-5$ & 0.0010 & $-5.85 e-6$ & 0.0003 \\
\hline Population & $\beta_{\mathrm{L}-\mathrm{POP}}$ & 0.2571 & 0.0431 & 0.3026 & 0.0604 \\
\hline Payroll & $\beta_{\mathrm{L}-\mathrm{PAY}}$ & 0.1071 & 0.0320 & -0.0113 & 0.0439 \\
\hline Per Capita Income & $\beta_{\mathrm{L}-\mathrm{INC}}$ & -0.2589 & 0.1627 & -0.0382 & 0.1594 \\
\hline City in a Top-Ten MSA & $\beta_{\mathrm{L}-\mathrm{MSA}}$ & 0.0560 & 0.1006 & -0.4954 & 0.1021 \\
\hline Incumbent $=\mathrm{RBOC}$ & $\beta_{\mathrm{L}-\mathrm{RBOC}}$ & -0.1153 & 0.0973 & 0.0361 & 0.0870 \\
\hline Regulatory Stringency & $\beta_{\mathrm{L}-\mathrm{REGEXP}}$ & 0.1010 & 0.0622 & 0.1409 & 0.0563 \\
\hline UNE-Loop Rate & $\beta_{\mathrm{L}-\text { LOOPRATE }}$ & -0.6436 & 0.1273 & 0.2396 & 0.1078 \\
\hline \multicolumn{6}{|l|}{ Effect on National CLECS } \\
\hline Constant & $\mathrm{C}_{\mathrm{N}}$ & -0.7525 & 0.1477 & 0.2563 & 0.1154 \\
\hline National Competitor \#1 & $\theta_{\mathrm{NN} 1}$ & -0.9810 & 0.0852 & -1.3600 & 0.0636 \\
\hline National Competitor \#2 & $\theta_{\mathrm{NN} 2}$ & -0.8007 & 0.1290 & -0.5024 & 0.0567 \\
\hline Local/Regional Competitor \#1 & $\theta_{\mathrm{NL1}}$ & $-2.53 e-5$ & 0.0012 & $-5.59 \mathrm{e}-5$ & 0.0018 \\
\hline Local/Regional Competitor \#2 & $\theta_{\mathrm{NL} 2}$ & $-3.48 \mathrm{e}-5$ & 0.0024 & $-9.29 \mathrm{e}-6$ & 0.0004 \\
\hline Local/Regional Competitor \#3 & $\theta_{\mathrm{NL} 3}$ & $-9.59 \mathrm{e}-6$ & 0.0010 & $-6.52 \mathrm{e}-5$ & 0.0005 \\
\hline Population & $\beta_{\mathrm{N}-\mathrm{P}}$ & 0.6312 & 0.0648 & 0.3479 & 0.0638 \\
\hline Payroll & $\beta_{\mathrm{N}-\mathrm{PAY}}$ & 0.2603 & 0.0482 & 0.2058 & 0.0526 \\
\hline Per Capita Income & $\beta_{\mathrm{N}-\mathrm{INC}}$ & -0.2436 & 0.2108 & 0.1324 & 0.1603 \\
\hline City in a Top-Ten MSA & $\beta_{\mathrm{N}-\mathrm{MSA}}$ & 0.4880 & 0.1294 & 0.0218 & 0.0952 \\
\hline Incumbent $=\mathrm{RBOC}$ & $\beta_{\mathrm{N}}-\mathrm{RBOC}$ & -0.2029 & 0.1282 & 0.2511 & 0.0964 \\
\hline Regulatory Stringency & $\beta_{\mathrm{N}-\text { REGEXP }}$ & -0.0803 & 0.0845 & -0.1167 & 0.0604 \\
\hline UNE-Loop Rate & $\beta_{\mathrm{N}}$ - LOOPRATE & 0.3077 & 0.1602 & -0.4598 & 0.1147 \\
\hline
\end{tabular}

type effect $\left(\theta_{L L 1}=-1.1903\right)$, but indicative of a greater tendency for national competitors to affect local CLECs in the most recent period. Nonetheless, the results for 1999 and 2002 strongly suggest that entry was more attractive for differentiated CLECs than for CLECs whose offerings were homogeneous, all else equal.

Finally, it is interesting to note how the various market-level explanatory variables have changed between the 1999 and 2002 estimates. As was suggested by the ordered probit results, the estimates for population, payroll, and income were relatively stable. The reduction in the effect of city in a top-ten MSA was similar across the two types. Interestingly, the regulatory variables appear to have a relatively greater impact on the national CLECs in 2002 than in 1999. This result appears both in the RBOC dummy variable - where the positive sign only appears for 2002 national firms - and for the UNE-Loop rate. Whereas in 1999 low rates tended to attract local/regional CLECs, by 2002 only the national CLECs see a negative and significant effect on this proxy for costs paid to ILECs. This has potentially interesting policy implications for regulators who may want to attract particular types of firms or encourage more entry in general. 
TABLEVIII

Market Evolution between I999 ANd 2002 — Ordered Probit

\begin{tabular}{|c|c|c|c|}
\hline & Coefficient & Standard Error & Z \\
\hline Population & $7.19 \mathrm{e}-7$ & $8.62 \mathrm{e}-7$ & 0.83 \\
\hline Payroll & $1.50 \mathrm{e}-7$ & $6.53 \mathrm{e}-8$ & 2.30 \\
\hline Per-capita Income & $8.76 \mathrm{e}-6$ & $6.52 \mathrm{e}-6$ & 1.34 \\
\hline City in Top-Ten MSA & -0.300 & 0.122 & -2.46 \\
\hline Incumbent $=\mathrm{RBOC}$ & 0.133 & 0.104 & 1.27 \\
\hline Regulatory Stringency & -0.497 & 0.069 & -0.72 \\
\hline Change in UNE-Loop Rate & -0.026 & 0.011 & -2.33 \\
\hline 1999 Planned & 0.395 & 0.062 & 6.39 \\
\hline 1999 Operating Residual & -0.275 & 0.064 & -4.27 \\
\hline 1999 Undifferentiated & -0.401 & 0.188 & -2.14 \\
\hline Number of Observations & \multicolumn{3}{|c|}{$\begin{array}{l}652 \text { total (at least one planned in 1999) } \\
138=-1(\# \text { operating '02 <\# operating '99) } \\
307=0(\# \text { operating '02 }=\# \text { operating '99) } \\
207=1(\# \text { operating '02 }>\# \text { operating '99) }\end{array}$} \\
\hline Psuedo- $\mathrm{R}^{2}$ & & 0.1142 & \\
\hline
\end{tabular}

Note: 1999 Operating Residual is calculated using the ordered probit estimates from Part A, Table VI. A negative value indicates that the actual number of operating firms is smaller than the model would predict. 1999 Undifferentiated is a dummy variable that equals 1 if the market is unbalanced with respect to the number of local and national firms operating. Specifically, if absolute_value (\# locals - \# nationals) is greater than 1, then 1999 Undifferentiated is set equal to 1.

\section{V (iii). Evolution of CLEC Markets: Inferences about Differentiation and Competition}

Recall that a conceptual profit function underlies the market structure observations, even though firms may have uncertainty about whether variable profits will exceed their costs of entry. To the extent that markets are not in equilibrium at the times of our analysis, we are more precisely measuring firms' expectations about profitability and how these expectations are affected by competition and differentiation. By separately estimating the market structure equilibrium before and after the valuation crash, we can be more confident that our inferences are based on successful entry decisions rather than on misguided expectations about what would determine profits in this industry. In addition, our parameter estimates may be biased to the extent that unobserved market characteristics are correlated with particular patterns of market composition. ${ }^{31}$

A few years after the millennium, it became apparent that some CLECs had been 'optimistic.' More precisely, some CLECs did not realize revenues sufficient to cover the debts incurred in building their facilities and

\footnotetext{
${ }^{31} \mathrm{We}$ would be concerned, for example, if such an unobserved characteristic favored differentiated market structures over undifferentiated ones. While the model allows us to control for the attractiveness of entry across markets for each type, we cannot specify such controls to be conditional on market structure and still obtain a unique equilibrium in the entry game.
} 
marketing their new services. ${ }^{32}$ Consequently, some CLECs continued their expansion, but with less publicity and fanfare. Others curtailed expansion plans they had announced in 1999 and previous years. There were a number of publicized bankruptcies among national firms, as well as many exits by smaller firms, which led to transfers of assets between hands. All these events, including those in the CLEC market, were popularly known as the 'telecom meltdown.'

The fortunes of particular firms did not necessarily track those of the distinct local markets. Total revenues for CLECs continued to grow between 1999 and 2002, even while the financial markets provided (dramatically) lower valuations for those firms that were publicly traded. Thus, as shown in Table II, the number of cities experiencing at least one CLEC entrant after 2002 was greater than that in 1999. Nonetheless, to increase confidence in our results, we analyzed data from both 1999 and 2002, just before and somewhat after the meltdown. If we had done such an exercise for a single cross-section (especially for CLECs in 1999) there might have been concern that miscalculations about the anticipated success of CLECs and the potential of pursuing particular forms of differentiation would influence the CLEC behavior in a way that ultimately did not last. In particular, incorporating the Stackelberg assumption into the entry model requires that the observations resemble a long-run equilibrim. By confirming that the differentiation results persist in a later cross-section, we are more certain that our inferences are not based on transitory factors.

We conclude with a look at city-level transitions, exploring how the structure of CLEC markets changed between 1999 and 2002. While most of the determinants of CLEC entry are stable over this short period, regulatory rulings and state decisions about interconnection pricing did change in many locales. We document these changes, and measure the sensitivity of entry and differentiated competition to them. In addition, if firms of one type prefer competing with those of a different type more than with the same type, then our modeling approach forecasts that market forces will give competitors incentives to respond. Here, we are interested in both how markets have changed and whether markets changed in a manner consistent with the importance of differentiated entry.

To avoid issues of selection, our analysis is limited to those cities where at least one CLEC was planned as of $1999 .{ }^{33}$ We classify these markets into

\footnotetext{
${ }^{32}$ The trade press dates the beginning of the decline of optimism at the spring of 2000, when financial support for dot.coms collapsed. This low continued through 2001 as the September 11 terrorist attack shook business confidence in long-term investments and into the spring of 2002 as the WorldCom financial scandal became publicized.

${ }^{33}$ In other words, the 652 observations in Table VIII include all but the first row of the raw data in Table III.
} 
three categories on the basis of the gross transitions: -1 if there were fewer operating CLECs in 2002 that in 1999, 0 if the number of operating firms is equal in the two years, and 1 if there was an increase in operating CLECs between 1999 and 2002. In Table VIII, we present an ordered probit on this market structure change variable. The first six variables in the table are the same market characteristics as were used in the previous analysis. The results are not surprising: most have little impact on market structure change, to the extent that they affected the number of CLECs operating in each time period similarly. An interesting exception is the negative and significant coefficient on the Change in UNE-Loop Rate variable, indicating that cities where regulators lowered these rates over time saw growth in the number of operating CLECs as compared to cities where these rates remained the same or increased.

The remaining three explanatory variables in Table VIII are intended to capture how the condition of the 1999 markets affected the 2002 market structure. First, we found that stated entry plans predicted market growth (such plans appear to have been followed up) despite the industry upheaval between 1999 and 2002. We also looked at predictions from the model by including the residual for each city from the 1999 ordered probit. A negative value of this variable indicates that the actual number of CLECs operating in 1999 was smaller than predicted. In terms of the model's estimates in 1999, those markets with fewer CLECs than predicted appeared to add firms, and vice versa, by 2002. Finally, we created a dummy variable 1999 Undifferentiated to identify markets that were unbalanced in 1999 — with the difference in the number of local/regional and national CLECs operating greater than one. For example, in cities with two operating CLECs, this dummy variable equaled 1 for those cities where both CLECs were the same type. All else being equal, we would expect undifferentiated market structures to be less sustainable because the undifferentiated firms were more competitive with each other. The negative and significant coefficient on this dummy variable in Table VIII conforms with our intuition regarding the returns to differentiation: all else equal unbalanced markets in 1999 tended to have fewer operating CLECs by 2002.

While these results fall far short of a true dynamic analysis of CLEC market structure, they do provide additional support for our interpretations regarding the importance of differentiation among CLECs. We show that in addition to shielding CLECs from competition in each period, differentiated CLEC market structures tend to remain more stable. We also find that despite the implosion in CLEC firms' values since 1999, the structure of CLEC markets has evolved in predictable ways over time. There has been more CLEC activity in cities where entry had been planned and where markets have not developed as quickly as expected by 1999. Finally, changes made by regulators have affected CLEC market entry, a factor that should 
be considered as regulators continue to deliberate over future changes to UNE rates paid by CLECs.

\section{CONCLUSION}

We present strong evidence of a consistent role for product differentiation in building and expanding markets for local telecommunications. Both before and after the valuation crash that disrupted many market participants, CLECs followed entry strategies that resulted in markets with significantly heterogeneous product types instead of markets dominated by firms of one type or another. This pattern suggests that successful CLECs were mindful about the characteristics of their competitors. It also suggests that they entered markets where their types of services were more attractive to consumers (and regulators) and where such factors were important to their success. Indeed, we find that CLEC heterogeneity shaped firm entry behavior as much as differences in local economic and regulatory conditions. While we have documented the value in distinguishing between local and national CLECs, we leave open the question about whether there are other important dimensions on which CLECs can differentiate.

We conclude that the literature on competitive local telephony should continue to investigate the many issues raised by the demonstrated importance of heterogeneity. While our model has focused on competition among CLECs, it has implications for analysis of competition between CLECs and ILEC. Just after the passage of the Telecom Act, it was common to portray CLECs as a homogeneous group, sometimes as a 'fringe' competitor to ILECs. Indeed, the FCC encourages such a portrayal when official reports present 'counts' of entrants without distinction between them. This is potentially misleading. Our findings stress that there is no necessary logical connection between use of similar inputs and the similarity of two CLECs' appeal to customers.

In other words, treating all CLECs as homogeneous gives the potentially false impression that CLECs are close substitutes for each other in demand. This is an open empirical issue to be investigated, not a proposition about competitive behavior to be presumed without evidence. Individual CLECs may not be competing for the same sets of demanders. Even if CLECs compete for residual demand from former ILEC customers, these residual customers may have different concerns, encouraging distinct CLEC competitive behavior. Related, the assumption about homogenous competition implies that two CLECs place the same type of pricing pressure on the ILEC. Yet, the price elasticity faced by the ILEC for two sets of marginal users may be quite different if each set of users cares about different offerings from different CLECs.

Our results have implications for policy discussion. For a variety of reasons, it may be difficult for an ILEC to effectively serve all types of 
heterogeneous customers equally. By opening up such markets to competition, firms targeting customers may enter and serve these customers better. Our results are consistent with the view that CLECs did just this. Policy makers should account for consumer welfare gains that result from better product targeting as well as from lower prices. While all procompetitive policies for local telephony support putting entrants through a market test, our results identify what ignoring differentiation can miss. Policy makers should not presume they know the formula for commercial success solely on the basis of observing ILECs and counting the number of incumbent CLECs. Instead they should identify CLEC strategies that differ from those of the ILEC and other CLECs, with the intent of encouraging firms that let consumers choose among an expanded array of options.

\section{REFERENCES}

Abel, J., 2002, 'Entry into Regulated Monopoly Markets: The Development of a Competitive Fringe in the Local Telephone Industry,' Journal of Law and Economics, 45, pp. 289-316.

Abel, J. and Clements, M., 2001, 'Entry Under Asymmetric Regulation,' Review of Industrial Organization, 19, pp. 227-42.

Bajari, P. and Fox, J. T., 2005, Complementarities and Collusion in an FCC Auction, (mimeo, University of Chicago).

Berry, S. T., 1992, 'Estimation of a Model of Entry in the Airline Industry,' Econometrica, 60, pp. 889-917.

Bresnahan, T. F. and Reiss, P. C., 1991, 'Entry and Competition in Concentrated Markets,' Journal of Political Economy, 99, pp. 977-1009.

Crandall, R. W., 2001, 'An Assessment of the Competitive Local Exchange Carriers Five Years after the Passage of the Telecommunications Act,' Report for the USTA by Criterion Economics, LLC., mimeo, Washington, D.C.

Crandall, R. W.; Ingraham, A. T. and Singer, H. J., 2004, 'Do Unbundling Policies Discourage CLEC Facilities-Based Investment?,' B.E. Journals in Economic Analysis and Policy.

Crandall, R. W. and Sidek, J. G., 2002, 'Is Structural Separation of Incumbent Local Exchange Carriers Necessary for Competition?', Yale Journal on Regulation, 19, pp. 1-75.

Economides, N.; Seim, K. and Viard, V. B., 2004, Quantifying the Benefits of Entry into Local Telephone Service, (mimeo, Stanford University).

Federal Communication Commission 'Local Telephone Competition,' Industry Analysis Division, Common Carrier Bureau, http://www.fcc.gov/wcb/iatd/comp.html, downloaded 8/2005.

Greenstein, S. and Mazzeo, M. J., 2003, 'Differentiation Strategy and Market Deregulation: Local Telecommunications Entry in the Late 1990s,' NBER Working Paper \#9761, Cambridge, Massachusetts.

Gregg, B. J., 2001, 2003, 'A Survey of Unbundled Network Element Prices in the United States, Public Service Commission of West Virginia,' http://www.cad.state.wv.us/ Une\%20Page.htm, downloaded 8/2005.

Jamison, M. A., 2004, Effects of Prices for Local Network Interconnection on Markets Structure in the U.S., (mimeo, University of Florida). 
Mazzeo, M. J., 2002, 'Product Choice and Oligopoly Market Structure,' Rand Journal of Economics, 33, pp. 221-42.

Mini, F., 2001, 'The Role of Incentives for Opening Monopoly Markets: Comparing GTE and BOC Cooperation with Local Entrants,' Journal of Industrial Economics, 49, pp. 379-413.

New Paradigm Resources Group, 2000, 1999 CLEC Report, $11^{\text {th }}$ ed Chicago, IL.

New Paradigm Resources Group, 2003, 2002 CLEC Report, $6^{\text {th }}$ ed Chicago, IL.

Rosston, G. and Wimmer, B., 2001, 'From C to Shining C Competition and CrossSubsidy in Communications,' in Compaine, B. and Greenstein, S. (eds.), Communications Policy in Transition: The Internet and Beyond, (MIT Press, Cambridge, Massachusetts).

Shiman, D. and Rosenworcel, J., 2002, 'Assessing the Effectiveness of Section 271 Five Years after the Telecommunications Act of 1996,' in Cranor, L. and Greenstein, S., eds., Communications Policy and Information Technology: Promises, Problems and Prospects, (MIT Press, Cambridge, Massachusetts).

Tamer, E. T., 2003, 'Incomplete Bivariate Discrete Response Model with Multiple Equilibria,' Review of Economic Studies, 70, pp. 147-167.

Wood, L.; Zarakas, W. and Sappington, D., 2004, 'Wholesale Pricing and Local Exchange Competition,' Info, 6, pp. 318-325.

Woroch, G., 2001, 'Local Network Competition,' in Cave, M.; Majumdar, S. and Vogelsang., I. eds., Handbook of Telecommunications Economics, Elsevier Publishing, Amsterdam.

Zolnierek, J.; Eisner, J. and Burton, E., 2001, 'An Empirical Examination of Entry Patterns in Local Telephone Markets,' Journal of Regulatory Economics, 19, pp. 143-59. 